\title{
The role of fructose-1,6-bisphosphatase 1 in abnormal development of ovarian follicles caused by high testosterone concentration
}

\author{
TAO LIU ${ }^{1-3}$, HAN ZHAO $^{1,2}$, JIANFENG WANG $^{1,2}$, XIN SHU $^{1,2}$, YUAN GAO $^{1,2}$, \\ XIAOLI MU ${ }^{1,2}$, FEI GAO ${ }^{4}$ and HONGBIN LIU ${ }^{1,2}$ \\ ${ }^{1}$ Center for Reproductive Medicine, Shandong Provincial Hospital Affiliated to Shandong University; \\ ${ }^{2}$ National Research Center for Assisted Reproductive Technology and Reproductive Genetics, Jinan, Shandong 250001; \\ ${ }^{3}$ Center for Reproductive Medicine, Tai'an Central Hospital, Tai'an, Shandong 271000; ${ }^{4}$ State Key Laboratory of \\ Stem Cell and Reproductive Biology, Institute of Zoology, Chinese Academy of Sciences, Beijing 100101, P.R. China
}

Received December 16, 2015; Accepted January 24, 2017

DOI: $10.3892 / \mathrm{mmr} .2017 .7463$

\begin{abstract}
The present study aimed to identify the molecular mechanisms underlying the effects of the fructose-1,6-bisphosphatase 1 (FBP1) signaling pathway within normal follicle development and in hyperandrogenism-induced abnormal follicle growth. To achieve this, murine primary follicles, granulosa cells (GCs) and theca-interstitial cells (TICs) were isolated, cultured in vitro and treated with a high concentration of androgens. A concentration of $1 \times 10^{-5} \mathrm{~mol} / \mathrm{l}$ testosterone was considerable to induce hyperandrogenism by MTT assay. All cells were divided into four groups, as follows: Control group, testosterone group, androgen receptor antagonist-flutamide group and flutamide + testosterone group. Flutamide was used in the present study as it blocks the effects of the androgen receptor. The mRNA expression levels of FBP1 were detected using reverse transcription-quantitative polymerase chain reaction. The expression levels and localization of FBP1 were analyzed by western blot analysis and immunofluorescence staining. The experimental results demonstrated that androgen presence stimulated follicle development, whereas excessive testosterone inhibited development. FBP1 was identified as being mainly expressed in follicles; FBP1 protein was significantly expressed in GCs of the 14-day-cultured follicle, as well as in the cytoplasm and nuclei of GCs and TICs in vitro. Testosterone increased FBP1 expression during a specific range of testosterone concentrations. Testosterone increased the expression of FBP1 within GCs. Furthermore, FBP1 and phosphoenolpyruvate carboxykinase 1 (PCK1) mRNA
\end{abstract}

Correspondence to: Dr Hongbin Liu, Center for Reproductive Medicine, Shandong Provincial Hospital Affiliated to Shandong University, 324 Jinwu Road, Jinan, Shandong 250001, P.R. China E-mail: humangenetics2008@hotmail.com

Key words: testosterone, fructose-1,6-bisphosphatase, follicle development, granulosa cell, theca-interstitial cell expression was increased in GCs treated with testosterone, whereas forkhead box protein $\mathrm{O} 1$ (FOXO1) and peroxisome proliferator-activated receptor $\gamma$ coactivator- $1 \alpha$ mRNA expression was significantly decreased in the testosterone group. In TICs, testosterone and flutamide inhibited the mRNA expression levels of FOXO1 and glucose-6-phosphatase enzyme, and promoted the expression of PCK1. These results suggested that the FBP1 signaling pathway may serve an important role in normal follicle growth and hyperandrogenism-induced abnormal development, which may be associated with abnormal glucose metabolism induced by high concentrations of testosterone.

\section{Introduction}

Androgens serve an essential role as autocrine or paracrine agents in mammalian ovarian follicle growth, maturation and luteinization (1). However, androgens have a dual role in follicle development. Low androgen concentrations promote follicle recruitment from the reserve pool into the development pool. This occurs by promoting theca-interstitial cell (TIC) and granulosa cell (GC) proliferation, and reducing follicle atresia and apoptosisby binding to androgen receptors on preantral follicles or small antral follicles (2). Conversely, high androgen concentrations may exert inhibitory effects, for example, hyperandrogenism-induced antral follicle arrest in rats (3). Hyperandrogenemia is associated with numerous clinical disorders, in which reproductive dysfunction and metabolic alterations coexist, for example, polycystic ovary syndrome (PCOS), obesity and congenital adrenal hyperplasia (4). Furthermore, there is growing evidence to suggest that the elevated levels of circulating androgens in girls with clinical obesity may lead to an increased neuroendocrine drive to the reproductive axis $(5,6)$. The etiology of PCOS is unclear, and ethical and logistic constraints limit decisive clinical studies. Consequently, treatment is palliative rather than curative, and focuses on symptomatic approaches. Heritable tendencies have previously been recognized, however complex interactions exist between genetic and environmental factors. Therefore, in 
order to identify causative genes, our previous study conducted a genome-wide association study (GWAS) of PCOS in a Han Chinese population (7). To the best of our knowledge, this study was the first to demonstrate that fructose-1,6-bisphosphatase (FBP1), luteinizing hormone/choriogonadotropin receptor, follicle-stimulating hormone receptor and insulin receptor are correlated with PCOS etiology (7).

Some physiological and metabolic abnormalities that are often reported to be associated with PCOS include gestational diabetes, impaired glucose tolerance, hyperinsulinemia and type 2 diabetes mellitus; thus, increasing the risk of morbidity and mortality. Previous studies onnon-human primates, sheep, rats and mice have suggested an epigenetic mechanism for PCOS based upon in utero exposure of the developing female fetus to androgen excess and associated metabolic consequences (8-10). Female rhesus monkeys exposed to excessive levels of prenatal androgens have presented the most comprehensive adult PCOS-like phenotype, meeting all three diagnostic criteria, in addition to the metabolic comorbidities of insulin resistance, impaired pancreatic beta cell function and increased prevalence of type 2 diabetes mellitus. Furthermore, this adult metabolic phenotype is preceded by excessive insulin sensitivity, increased insulin secretion relative to insulin sensitivity in infancy and increased glucose clearance rate (11).

FBP1 is a key regulatory enzyme of gluconeogenesis that catalyzes the hydrolysis of fructose-1,6-bisphosphate to fructose-6-phosphate and inorganic phosphate. FBP1 is a critical protein, since most glucose consumption and energy use of vital organs is dependent on gluconeogenesis. FBP1 deficiency is associated with fasting hypoglycemia and metabolic acidosis due to impaired gluconeogenesis (12). Following stimulation of human breast cancer cells with estradiol, the expression of the FBP1 protein increased (13). In addition, exposure of fetuses to sustained hypoglycemia resulted in maintenance of hepatic insulin action and increased FBP1 expression (14).

In the present study, an in vitro testosterone model was used, as it exhibits the main features of the hyperandrogenism phenotype in PCOS. Therefore, this model has been applied to mimic human PCOS $(15,16)$. Murine primary follicles, GCs and TICs were cultured in vitro and treated with a high concentration of androgens. The molecular mechanisms underlying the effects of the FBP1 signaling pathway onnormal follicle development and hyperandrogenism-induced abnormal follicle growth were investigated. These findings may provide a theoretical basis forthe mechanism of PCOS, and information regarding clinical prevention, diagnosis and genetic counseling.

\section{Materials and methods}

Animals. Female Kunming mice $[\mathrm{n}=200$; age, 14 days (weight, 8-10 g) and 26-28 days (weight, 17-20 g)] were purchased from the Animal Facility of Shandong University (Jinan, China) and housed in a 12-h light/12-h dark cycle (lights on at 7 a.m., off at 7 p.m.). Food and water were given. The present study was ethically approved by the Center for Reproductive Medicine, Shandong University (Jinan, China).

Isolation and culture of primary follicles. Primary follicle cells were cultured in operating liquid, containing $\alpha$-minimum
Essential medium ( $\alpha$-MEM; Hyclone; GE Healthcare Life Sciences, Logan, UT, USA), supplemented with $10 \%$ heat-inactivated fetal bovine serum (FBS; Hyclone; GE Healthcare Life Sciences), $100 \mathrm{U} / \mathrm{ml}$ penicillin and $100 \mu \mathrm{g} / \mathrm{ml}$ streptomycin sulfate. Culture medium I: $\alpha$-MEM supplemented with $10 \%$ FBS, ITS-mix (insulin $5 \mathrm{mg} / \mathrm{ml}$, transferrin $5 \mathrm{mg} / \mathrm{ml}$, selenium $5 \mathrm{ng} / \mathrm{ml}$; Sigma-Aldrich; Merck KGaA, Darmstadt, Germany) and $100 \mathrm{mU} / \mathrm{ml}$ recombinant follicle-stimulating hormone (FSH; Livzon Pharmaceutical Group Co., Ltd., Zhuhai, China) and luteinizing hormone (LH; Merck Serono GmbH, Darmstadt, Germany). Culture medium II was the same as culture medium I, with the omission of $\alpha$-MEM supplemented with 5\% FBS. Follicle culture was prepared as previously reported (17).

The 14-day-old mice were sacrificed by cervical dislocation prior to rapid dissection of the ovaries, which were placed in DMEM/F12 medium supplemented with $10 \%$ FBS, $100 \mathrm{IU} / \mathrm{ml}$ penicillin and $100 \mu \mathrm{g} / \mathrm{ml}$ streptomycin (all from Sigma-Aldrich; Merck KGaA). The tissue adhering to ovaries was removed using the beveled edges of two syringe needles. The ovaries were transferred into the operating liquid and were mechanically dissected again with two syringe needles. Follicles with one layer of GCs, a centrally placed oocyte, an intact basal membrane and some attached theca cells were collected and cultured individually in $10 \mu \mathrm{l}$ culture medium I, overlying paraffin oil (Sigma-Aldrich; Merck $\mathrm{KGaA})$. The culture dishes were maintained at $37^{\circ} \mathrm{C}$ in an incubator containing $100 \%$ humidity and $5 \% \mathrm{CO}_{2}$. Following 4 days of culturing, $10 \mu \mathrm{l}$ culture medium I was added to each cultured cell type. At 6 days, medium I was changed to culture medium II. Subsequent refreshment was conducted every other day by removing and replacing $10 \mu 1$ media. Follicular morphology was recorded using an inverted microscope prior to each refreshment.

Isolation of GCs and TICs. The GCs and TICs were collected as previously reported (18). GCs were isolated from the ovaries of 14-day-old mice. Following mechanical dissection, follicles were digested in a medium containing $1 \mathrm{mg} / \mathrm{ml}$ collagenase I, $0.025 \%$ trypsin and $0.02 \mathrm{mg} / \mathrm{ml}$ DNase I (Sigma-Aldrich; Merck KGaA) for $30-45 \mathrm{~min}$ at $37^{\circ} \mathrm{C}$. After 2 washes, the cells were seeded with Dulbecco's modified Eagle's medium (DMEM)/F12 (Hyclone; GE Healthcare Life Sciences) supplemented with $5 \%$ FBS, $100 \mathrm{IU} / \mathrm{ml}$ penicillin and $100 \mu \mathrm{g} / \mathrm{ml}$ streptomycin sulfate, and cultured overnight for adhesion. Following this period, the cells were cultured in fresh medium in the presence or absence of the various reagents for the indicated durations.

The TICs were isolated from the ovaries of 26-28-day-old mice. The ovaries were isolated from connective tissues under a stereomicroscope and were collected in culture medium (DMEM supplemented with $10 \%$ FBS, $100 \mathrm{U} / \mathrm{ml}$ penicillin, $0.1 \mathrm{mg} / \mathrm{ml}$ streptomycin, and $100 \mathrm{ng} / \mathrm{ml}$ recombinant FSH). The follicles on the surface of the ovaries were punctured with fine tweezers to remove GCs and oocytes. The punctured ovaries were cut into $1 \mathrm{~mm}^{3}$ fragments using scissors in culture medium containing $0.2 \%$ collagenase and $0.1 \%$ DNase, and were then pipetted to facilitate cell dispersion. The suspension of ovarian fragments was incubated at $37^{\circ} \mathrm{C}$ for $20 \mathrm{~min}$ and pipetted at the 10th and 20th min. Ovarian fragments, follicles 
and oocytes that could not be removed by puncturing with fine tweezers were filtered through a series of nylon meshes (pore size order, 155, 82, 40, 20 and $10 \mu \mathrm{m}$ ). The resulting cell suspension was centrifuged at $250 \mathrm{x}$ g at $4^{\circ} \mathrm{C}$ for $5 \mathrm{~min}$, and the supernatant was removed. To reduce the effects of collagenase to a negligible level, the above washing procedure was repeated 4 times. Finally, the cells were suspended in the culture medium, and the number of viable cells was counted by trypan blue exclusion test.

Effects of testosterone on follicle growth. According to a previous report (19), $1 \times 10^{-5} \mathrm{~mol} / 1$ testosterone (Sigma-Aldrich; Merck KGaA) was considered able to induce hyperandrogenism; therefore, the present study selected $1 \times 10^{-6}, 1 \times 10^{-5}$ and $1 \times 10^{-4} \mathrm{~mol} / 1$ as test doses, and observed follicle development for 14 days to determine the optimum dosage.

MTT assay analysis. GCs and TICs were seeded $\left(1 \times 10^{4}\right.$ cells/well) in 96-well plates and incubated in fresh medium with various reagents. Cells were treated with $1 \times 10^{-7}$, $1 \times 10^{-6}, 1 \times 10^{-5}, 1 \times 10^{-4}$ or $1 \times 10^{-3} \mathrm{~mol} / 1$ testosterone for 24 and $48 \mathrm{~h}$, and cell proliferation was monitored by MTT assay to determine the optimum dose. A total of $20 \mu \mathrm{l}$ MTT reagent wasadded to each well of the 96-well plate and incubated at $37^{\circ} \mathrm{C}$ for $4 \mathrm{~h}$, the supernatant was then removed and the cells were treated with $150 \mu \mathrm{l} /$ well dimethyl sulfoxide for $10 \mathrm{~min}$. Absorbance (optical density) was recorded at $570 \mathrm{~nm}$ using an ELISA plate reader.

Experimental group design. The optimum dosage of testosterone and flutamide was determined as $1 \times 10^{-5} \mathrm{~mol} / \mathrm{l}$ testosterone and flutamide, according to the aforementioned experiments and previously published papers $(20,21)$. Flutamide was used in the present study as it is an androgen receptor antagonist which reverses the effects of androgens $(20,21)$. Follicles, GCs and TICs were divided into the following groups: Control (CTR), testosterone (T), flutamide (F) and flutamide + testosterone $(\mathrm{F}+\mathrm{T})$ groups. The GCs and TICs of each group were treated with testosterone for $48 \mathrm{~h}$ at $37^{\circ} \mathrm{C}$. The follicles and cells in the $\mathrm{F}+\mathrm{T}$ group were treated with flutamide for $2 \mathrm{~h}$ prior to the addition of testosterone to their culture medium.

Hormone level measurement. The supernatant of cultured follicles was collected via centrifugation at $200 \mathrm{x}$ g for $5 \mathrm{~min}$ at $4^{\circ} \mathrm{C}$, in order to detect the levels of estradiol $\left(E_{2}\right)$, progesterone $(\mathrm{P})$ and insulin (INS) by chemiluminescence assay (cat. no. Unicel DXI800; Beckman Coulter, Inc., Brea, CA, USA) on day 7 and 14 in vitro.

RNA extraction and reverse transcription-quantitative polymerase chain reaction $(R T-q P C R)$. The mRNA expression levels of genes associated with FPB1, including FBP1, glucose-6-phosphatase catalytic subunit (G6 PC), phosphoenolpyruvate carboxykinase 1 (PCK1) and forkhead box protein $\mathrm{O} 1$ (FOXO1) were detected by RT-qPCR. Follicles and cells were initially lysed with TRIzol ${ }^{\circledR}$ reagent (Invitrogen; Thermo Fisher Scientific, Inc., Waltham, MA, USA). Total RNA was extracted according to the manufacturer's instructions. Total RNA $(1 \mu \mathrm{g})$ was reverse transcribed in a final volume of $20 \mu \mathrm{l}$ containing random primers (Takara Bio, Inc., Otsu, Japan), 5X PrimeScript Buffer 2.0 $\mu$ l, PrimeScript RT Enzyme Mix I $1.0 \mu \mathrm{l}$, Oligo dT Primer $(50 \mu \mathrm{M}) 1.0 \mu \mathrm{l}$, Random 6 mers $(100 \mu \mathrm{M}) 1.0 \mu \mathrm{l}$ and RNase Free $\mathrm{dH}_{2} \mathrm{O}$ up to $20 \mu \mathrm{l}$ (all from Takara Biotechnology Co., Ltd., Dalian, China). qPCR was performed using SYBR Premix Ex Taq (Takara Bio, Inc.) according to the manufacturer's instructions. The primer pairs used for RT-qPCR were as follows: FBP1 forward, TCAACT GCTTCATGCTGGAC and reverse, GGGTCAAAGTCCTTG GCATA; G6PC forward, GGTCCTGGACACCGACTACT and reverse, TGGCTTTTTCTTTCCTCGAA; PCK1 forward, TGACTCGGATGGGCATATCT and reverse, CATATCCGC TTCCAAAGGAG; FOXO1 forward, AAGAGCGTGCCC TACTTCAA and reverse, CTCCCTCTGGATTGAGCATC; and GAPDH forward, GACAGTCAGCCGCATCTTCT and reverse, TTAAAAGCAGCCCTGGTGAC. RT-qPCR was conducted using a LightCycler ${ }^{\circledR} 480$ sequence detection system (Roche Diagnostics, Basel, Switzerland). A total of $2 \mu \mathrm{l}$ cDNA was used for qPCR and the thermocycling conditions applied were as follows: $95^{\circ} \mathrm{C}$ for $15 \mathrm{sec}$, followed by 45 cycles of $95^{\circ} \mathrm{C}$ for $5 \mathrm{sec}$ and $60^{\circ} \mathrm{C}$ for $20 \mathrm{sec}$, then $95^{\circ} \mathrm{C}$ for $1 \mathrm{~min}$ and cooling to $55^{\circ} \mathrm{C}$. The mRNA expression levels were normalized to GAPDH mRNA and results were analyzed using the $2^{-\Delta \Delta C q}$ method (22).

Western blot analysis. FBP1 protein expression was analyzed by western blot analysis. Cells were collected and lysed in SDS sample buffer [62.5 mM Tris- $\mathrm{HCl}$ (pH 6.8), 3\% SDS, $10 \%$ glycerol, $50 \mathrm{mM}$ DL-dithiothreitol and $0.1 \%$ bromophenol blue] with protease inhibitors (Roche Diagnostics, Indianapolis, IN, USA). Total proteins were quantified using a bicinchoninic acid kit (Pierce; Thermo Fisher Scientific, Inc.) according to the manufacturer's instructions. Protein samples were boiled at $100^{\circ} \mathrm{C}$ in loading buffer for $10 \mathrm{~min}$, then $10 \mu \mathrm{g}$ protein from each sample $(1 \mu \mathrm{g} / \mu \mathrm{l}, 10 \mu \mathrm{l})$ was electrophoresed through a precast gel (NuPAGE Novex 4-12\% Bis-Tris gel; $1.5 \mathrm{~mm}$; 10 wells; Invitrogen; Thermo Fisher Scientific, Inc.). Proteins were transferred from the gel to a polyvinylidene difluoride membrane (EMD Millipore, Billerica, MA, USA) by means of the semidry technique using the Criterion Blotter (Bio-Rad Laboratories, Inc., Hercules, CA, USA) at $100 \mathrm{~V}$ for 60 min and blocked with 5\% milk in PBS (pH 7.4) containing $0.05 \%$ Tween-20.

The membranes were incubated overnight at $4^{\circ} \mathrm{C}$ with rabbit anti-FBP1 (cat. no. ab109020; Abcam, Cambridge, UK) diluted to $1 \mu \mathrm{g} / \mathrm{ml}$ and anti- $\beta$-actin (cat. no. A5441, 1:200; Sigma-Aldrich; Merck KGaA) antibodies. After washing with TBST [25 mM Tris- $\mathrm{HCl}$ (pH 7.5), $137 \mathrm{mM} \mathrm{NaCl}, 2.7 \mathrm{mM} \mathrm{KCl}$ and $0.05 \%$ Tween-20], the membrane was incubated at $37^{\circ} \mathrm{C}$ with alkaline peroxidase-conjugated affinipure goat anti-rabbit immunoglobulin G (IgG; cat. no. 111-035-003, 1:10,000; Jackson ImmunoResearch Laboratories, Inc., West Grove, PA, USA) for $1 \mathrm{~h}$. The proteins were detected with an enhanced chemiluminescence system (Pierce; Thermo Fisher Scientific, Inc.). Semi-quantitative analysis of western blotting was conducted using the Image Quant-TL software (version 7.0; GE Healthcare Life Sciences, Pittsburgh, PA, USA).

Immunofluorescence staining. Follicles were cultured in 96-well culture slides, and the GCs and TICs were grown 
in 4-well culture slides until they reached $70 \%$ confluence. Following washing 3 times with PBS (5 min/wash), the cells were fixed with freshly prepared $4 \%$ paraformaldehyde diluted in PBS for $10 \mathrm{~min}$ at room temperature. The fixative solution was aspirated, and the cells were washed with PBS before being blocked with $10 \%$ normal goat serum (Sigma; Merck KGaA) for $1 \mathrm{~h}$ at room temperature. Briefly, $0.1 \%$ Triton $\mathrm{X}-100 / \mathrm{PBS}$ was applied to the cells for $5 \mathrm{~min}$. The primary antibodies were diluted in PBS $+10 \%$ goat serum and applied to the cells overnight at $4^{\circ} \mathrm{C}$. The following antibody was used: Rabbit anti-FBP1 (1:200, cat. no. ab109020; Abcam). After 3 washes with PBS (5 min/wash), goat anti-mouse fluorescein isothiocyanate-conjugated $\operatorname{IgG}$ secondary antibody (1:200, cat. no. ab31430; Abcam) was applied, and the samples were incubated in the dark for $1 \mathrm{~h}$ at room temperature. Following this incubation, the cells were washed three times with PBS containing $0.1 \%$ Tween-20 and the cells were then washed with PBS. Finally, slides were counterstained with nuclear DAPI staining for $2.5 \mathrm{~h}$ at $4^{\circ} \mathrm{C}$ in the dark (Sigma-Aldrich; Merck KGaA), mounted with a coverslip using VECTASHIELD ${ }^{\circledR}$ Hard Set Mounting Medium with DAPI and observed under a fluorescence image analyzer (cat. no. CKX41; Olympus Corporation, Tokyo, Japan). The following negative control conditions were also included: No primary antibody and no secondary antibody.

Immunohistochemistry of ovarian tissues. Immunohistochemistry was performed on ovarian tissue from 14-day-old mice with rabbit anti-FBP1 (1:200, cat. no. ab109020; Abcam) and isotype IgG (1:100, cat. no. sc-2028; Santa Cruz Biotechnology, Inc., Dallas, TX, USA). The ovarian tissues were fixed in $10 \%$ formalin at $4^{\circ} \mathrm{C}$ for $24 \mathrm{~h}$, embedded in paraffin and then the slides were cut in triplicate $(5-\mu \mathrm{m}$ thick sections); one slide was processed for immunohistochemistry with the FBP1 antibody and the second slide was processed with isotype $\operatorname{IgG}$ as a control. Formalin-fixed paraffin-embedded sections were incubated at $60^{\circ} \mathrm{C}$ for $30 \mathrm{~min}$, deparaffinized in xylene and rehydrated by washing with an ethanol gradient (100\% then 95\%) and water. Antigen retrieval (boiling for $10 \mathrm{~min}$ in $10 \mathrm{mM}$ sodium citrate, $\mathrm{pH}$ 6.0) and peroxidase quenching $(0.3 \%$ hydrogen peroxide treatment for $10 \mathrm{~min})$ were also performed. Sections were incubated in Blocking Buffer (PBS with 5\% normal goat serum (cat. no. ZLI-9021; ZSGB-BIO; OriGene Technologies, Inc., Beijing, China), 0.5\% bovine serum albumin (cat. no. A6003-25G; Sigma; Merck $\mathrm{KGaA}$ ) and $0.1 \%$ Triton $\mathrm{X}-100$ ) for $45 \mathrm{~min}$ at room temperature and then incubated at $4^{\circ} \mathrm{C}$ with rabbit anti-FBP1 (1:200, cat. no. ab109020; Abcam) overnight. Followed by incubation for $30 \mathrm{~min}$ at room temperature with biotinylated goat anti-rabbit IgG (1:300) Vectastain ABC elite (cat. no. BA-1000; Vector Laboratories, Inc., Burlingame, CA, USA). All of the slides were examined using a Nikon Eclipse E800 microscope (Nikon Corporation, Tokyo, Japan).

Statistical analysis. Experiments were repeated at least three times and the results are expressed as the mean \pm standard deviation. The data were evaluated for statistical differences using SPSS (version 18.0; SPSS Inc., Chicago, IL, USA). One-way analysis of variance followed by a least-significant-difference test was used for statistical comparisons among multiple groups. $\mathrm{P}<0.05$ was considered to indicate a statistically significant difference.

\section{Results}

Testosterone promotes the development of cultured follicles in vitro. To determine the function of testosterone on follicle development, primary follicles isolated from ovaries of 14-day-old mice were cultured in vitro and treated with various doses of testosterone. As presented in Fig. 1, the effects of $1 \times 10^{-6}, 1 \times 10^{-5}$ and $1 \times 10^{-4} \mathrm{~mol} / 1$ testosterone on mice primary follicles were observed in vitro under an inverted microscope, and it was identified that all three concentrations of testosterone promoted follicle development at an early stage (day 7), but eventually inhibited follicle growth at a later stage (days 7-14). There were no significant differences amongthe three groups $(\mathrm{P}>0.05)$; therefore, $1 \times 10^{-5} \mathrm{~mol} / 1$ testosterone was chosen for subsequent experiments using follicles, according to the preliminary test and in reference to published literature (Fig. 1; Tables I and II) (20).

Testosterone induces the proliferation of GCs and TICs in vitro. Cultured GCs and TICs were treated with testosterone and cell proliferation was analyzed by MTT assay. As presented in Fig. 2, 1x10 $0^{-3} \mathrm{~mol} / 1$ testosterone inhibited GC proliferation, whereas GC growth was significantly promoted following 24 and $48 \mathrm{~h}$ treatment with the other testosterone concentrations $(\mathrm{P}<0.05)$. In addition, $1 \times 10^{-6}$ and $1 \times 10^{-5} \mathrm{~mol} / 1$ testosterone promoted TIC proliferation, whereas cell growth in the $1 \times 10^{-4}$ and $1 \times 10^{-3} \mathrm{~mol} / 1$ testosterone groups was significantly inhibited ( $\mathrm{P}<0.05$; Fig. 2). Therefore, $10^{-5} \mathrm{~mol} / 1$ testosterone treatment for $48 \mathrm{~h}$ was chosen for follow-up experiments on GCs and TICs.

Effects of testosterone on hormone secretion in follicles. As presented in Table III, on day $7 \mathrm{E}_{2}, \mathrm{P}$ and INS levels were significantly higher in the follicle supernatant of the $\mathrm{T}$ group when compared with the CTR group $(\mathrm{P}<0.05)$; however, only $\mathrm{E}_{2}$ and INS levels were significantly higher inthe $\mathrm{F}+\mathrm{T}$ group when compared with the CTR group $(\mathrm{P}<0.05)$. On day 14 , the follicle supernatant of eachgroup was analyzed and it was indentifed that the levels of $\mathrm{E}_{2}$ and $\mathrm{P}$ in the $\mathrm{T}$ group, $\mathrm{E}_{2}$ and INS in the $\mathrm{F}$ group, and $\mathrm{E}_{2}$ in the $\mathrm{F}+\mathrm{T}$ group were significantly higher compared with in the CTR group $(\mathrm{P}<0.05)$.

Ovarian expression of FBP1. FBP1 protein expression was detected by immunohistochemical staining of ovarian tissue sections from 14-day-old mice. The results demonstrated that FBP1 was primarily expressed in the ovarian oocytes, GCs and TICs. FBP1 protein was markedly expressed in the GCs of follicles that were cultured for 14 days, and the cytoplasm and nuclei of GCs and TICs in vitro (Fig. 3).

Effects of testosterone on FBPI mRNA expression in GCs. Using RT-qPCR, it was demonstrated that various concentrations of testosterone had a significant impact on the mRNA expression of FBP1 in GCs. The mRNA expression levels of FBP1 were significantly higher in GCs treated with testosterone compared with in the CTR group, with the exception of the $1 \times 10^{-7} \mathrm{~mol} / 1$ testosterone-treated group $(\mathrm{P}<0.05)$. In addition, 
Table I. Effects of various concentrations of testosterone on follicle diameter.

\begin{tabular}{|c|c|c|c|c|c|}
\hline \multirow[b]{2}{*}{ Group } & \multirow[b]{2}{*}{ Total follicle number } & \multicolumn{2}{|l|}{7 days } & \multicolumn{2}{|l|}{14 days } \\
\hline & & Mean diameter $(\mu \mathrm{m})$ & $\mathrm{P}$-value & Mean diameter $(\mu \mathrm{m})$ & P-value \\
\hline CTR & 30 & $100.0 \pm 2.3$ & & $521.3 \pm 3.3$ & \\
\hline $\mathrm{T} 10^{-6} \mathrm{~mol} / \mathrm{l}$ & 30 & $130.2 \pm 5.7^{\mathrm{a}}$ & 0.043 & $462.3 \pm 2.9^{a}$ & 0.049 \\
\hline $\mathrm{T} 10^{-5} \mathrm{~mol} / \mathrm{l}$ & 30 & $138.5 \pm 2.2^{\mathrm{a}}$ & 0.035 & $433.4 \pm 5.3^{\mathrm{a}}$ & 0.033 \\
\hline $\mathrm{T} 10^{-4} \mathrm{~mol} / \mathrm{l}$ & 30 & $146.7 \pm 6.2^{\mathrm{a}}$ & 0.019 & $332.8 \pm 7.1^{\mathrm{a}}$ & 0.008 \\
\hline
\end{tabular}

Follicle diameter following treatment with $1 \times 10^{-6}, 1 \times 10^{-5}$ or $1 \times 10^{-4} \mathrm{~mol} / 1$ testosterone was significantly increased at day 7 compared with the CTR group. However, follicle diameter was decreased by testosterone treatment at day $14 .{ }^{a} \mathrm{P}<0.05$ vs. CTR group. CTR, control (no testosterone treatment); T, testosterone treatment group.

Table II. Effects of various concentrations of testosterone on follicle development.

\begin{tabular}{|c|c|c|c|c|c|}
\hline \multirow[b]{2}{*}{ Group } & \multirow[b]{2}{*}{$\begin{array}{c}\text { Total follicle } \\
\text { number }\end{array}$} & \multicolumn{2}{|c|}{7 days } & \multicolumn{2}{|c|}{14 days } \\
\hline & & $\begin{array}{l}\text { Live follicle } \\
\text { number }(\%)\end{array}$ & $\begin{array}{l}\text { Arrested follicle } \\
\text { number }(\%)\end{array}$ & $\begin{array}{l}\text { Live follicle } \\
\text { number }(\%)\end{array}$ & $\begin{array}{l}\text { Arrested follicle } \\
\text { number }(\%)\end{array}$ \\
\hline CTR & 30 & $29(96.67)$ & $1(3.33)$ & $29(96.67)$ & $1(3.33)$ \\
\hline $\mathrm{T} 10^{-6} \mathrm{~mol} / \mathrm{l}$ & 30 & $27(90.00)$ & $3(10.00)$ & $26(86.67)$ & $4(13.33)$ \\
\hline $\mathrm{T} 10^{-5} \mathrm{~mol} / \mathrm{l}$ & 30 & $26(86.67)$ & $4(13.33)$ & $25(83.33)$ & $5(16.67)$ \\
\hline $\mathrm{T} 10^{-4} \mathrm{~mol} / \mathrm{l}$ & 30 & $24(80.00)$ & $6(20.00)^{\mathrm{a}}$ & $22(73.33)$ & $8(26.67)^{\mathrm{a}}$ \\
\hline
\end{tabular}

The percentage of arrested follicles was significantly increased following treatment with $1 \times 10^{-4} \mathrm{~mol} / \mathrm{l}$ of testosterone treatment at days 7 and 14 compared with the CTR group. ${ }^{a} \mathrm{P}<0.05$ vs. CTR group. CTR, control (no testosterone treatment); T, testosterone treatment group.
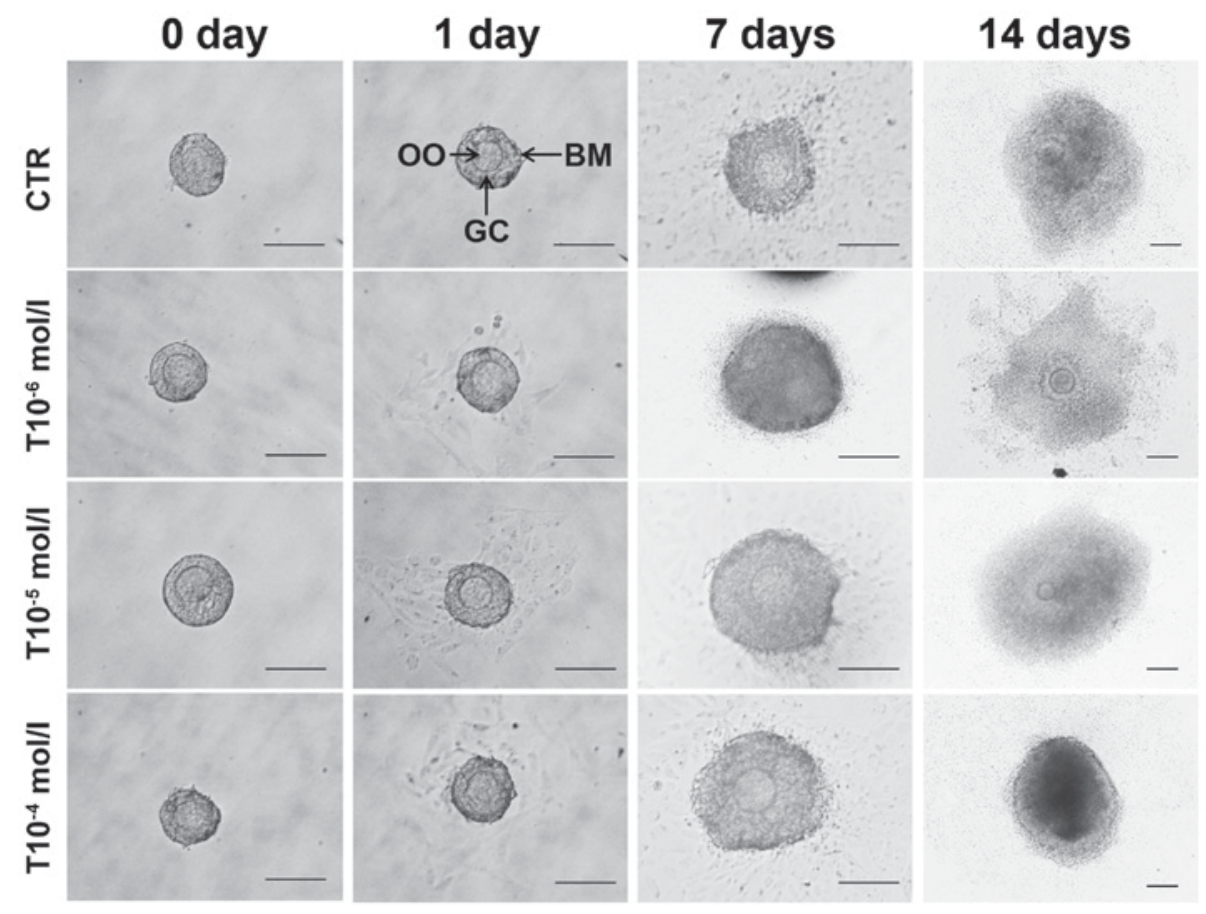

Figure 1. Effects of testosterone on follicle development in vitro. Primary follicles were treated with various concentrations of testosterone $\left(\mathrm{T} 10^{-6}, \mathrm{~T} 10^{-5}\right.$ and $\left.\mathrm{T} 10^{-4} \mathrm{~mol} / \mathrm{l}\right)$. The photomicrographs illustrate the morphological and size changes in follicles. The OO are centrally located within a single layer of GCs, a few stromal cells remain with the follicle at day 7. Following 7 days in culture the follicles were observed and photographed, and the follicle had increased by $\sim 40 \%$ in diameter. By day 14 , the follicle treated with concentrations of testosterone $\left(\mathrm{T} 10^{-6}, \mathrm{~T} 10^{-5}\right.$ and $\left.\mathrm{T} 10^{-4} \mathrm{~mol} / \mathrm{l}\right)$ further increased in diameter by $\sim 8$-fold All three concentrations of testosterone promoted follicle developmentup today 7, but eventually inhibited follicle growth betweendays 7 and 14 . There were no significant differences in diameter among the testosterone-treated groups ( $\mathrm{P}>0.05)$. CTR, control group (no testosterone treatment); T, testosterone treatment group; OO, oocytes; BM, basement membrane; GC, granulosa cell. Scale bar, $100 \mu \mathrm{m}$. 
Table III. Effects of testosterone on follicular hormone secretion in vitro.

\begin{tabular}{|c|c|c|c|c|c|c|}
\hline \multirow[b]{2}{*}{ Group } & \multicolumn{3}{|c|}{7 days } & \multicolumn{3}{|c|}{14 days } \\
\hline & $\mathrm{E}_{2}(\mathrm{pg} / \mathrm{ml})$ & $\mathrm{P}(\mathrm{ng} / \mathrm{ml})$ & INS (mIU/l) & $\mathrm{E}_{2}(\mathrm{pg} / \mathrm{ml})$ & $\mathrm{P}(\mathrm{ng} / \mathrm{ml})$ & INS (mIU/l) \\
\hline CTR & $334.50 \pm 10.12$ & $0.41 \pm 0.08$ & $170.80 \pm 10.11$ & $2,356.25 \pm 50.98$ & $10.15 \pm 1.21$ & $148.00 \pm 12.31$ \\
\hline $\mathrm{T}$ & $4,300.00 \pm 20.86^{\mathrm{a}}$ & $0.80 \pm 0.06^{\mathrm{a}}$ & $355.10 \pm 21.25^{\mathrm{a}}$ & $5,300.00 \pm 43.87^{b}$ & $18.57 \pm 2.13^{b}$ & $194.38 \pm 11.09$ \\
\hline $\mathrm{F}$ & $73.50 \pm 4.11^{\mathrm{a}}$ & $0.17 \pm 0.02^{\mathrm{a}}$ & $323.50 \pm 29.87^{\mathrm{a}}$ & $5,221.11 \pm 39.97^{b}$ & $11.68 \pm 0.99$ & $459.10 \pm 20.31^{b}$ \\
\hline $\mathrm{F}+\mathrm{T}$ & $4,300.00 \pm 38.78^{a}$ & $0.52 \pm 0.09$ & $321.50 \pm 30.01^{\mathrm{a}}$ & $4,997.35 \pm 50.22^{b}$ & $13.13 \pm 0.97$ & $183.30 \pm 20.76$ \\
\hline
\end{tabular}

On day $7, \mathrm{E}_{2}, \mathrm{P}$ and INS levels were significantly higher in the follicle supernatant of the T group compared with the CTR group; ${ }^{\mathrm{a}}<0.05$ vs. CTR group; however, only $\mathrm{E}_{2}$ and INS levels were significantly higher in the $\mathrm{F}+\mathrm{T}$ group compared with in the CTR group. ${ }^{\mathrm{a}} \mathrm{P}<0.05$ vs. CTR group. $\mathrm{E}_{2}$ and $\mathrm{P}$ levels in the T group, $\mathrm{E}_{2}$ and INS levels in the $\mathrm{F}$ group and $\mathrm{E}_{2}$ levels in the $\mathrm{F}+\mathrm{T}$ group were significantly higher than in the CTR group on day $14 .{ }^{b} \mathrm{P}<0.05$ vs. CTR group after 14 days. CTR, control (no testosterone treatment); T, testosterone treatment group; F, flutamide treatment group; F+T, flutamide + testosterone group; INS, insulin.

A

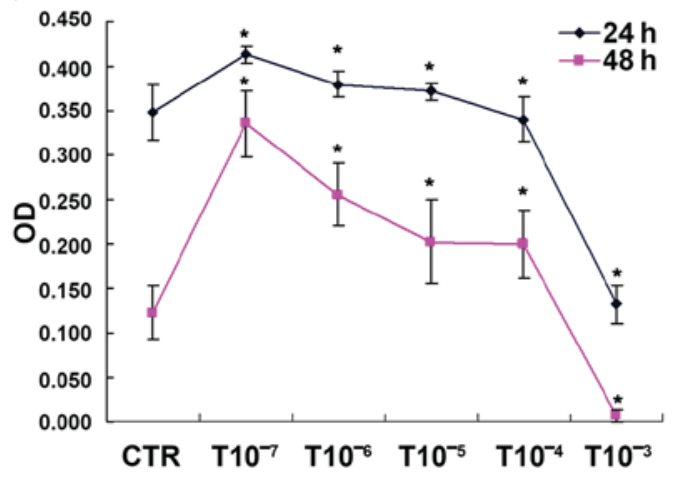

B

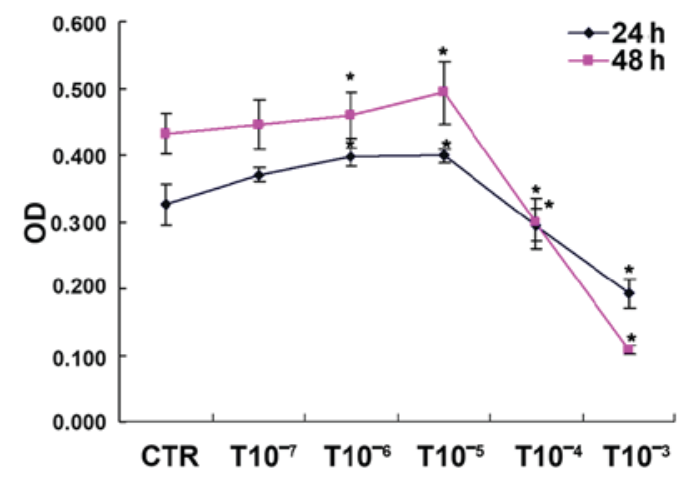

Figure 2. Effects of testosterone on the proliferation of GCs and TICs, as determined using an MTT assay. (A) GC proliferation and (B) TIC proliferation was determined following treatment with various concentrations of testosterone. ${ }^{*} \mathrm{P}<0.05$ vs. CTR group. CTR, control group (no testosterone treatment); T, testosterone treatment group; OD, optical density; GC, granulosa cell; TIC, theca-interstitial cell.

FBP1 expression was detected following treatment of GCs with $1 \times 10^{-5} \mathrm{~mol} / 1$ testosterone for various durations; the mRNA expression levels ofFBP1 were significantly increased in GCs treated with testosterone for 2, 12 and $48 \mathrm{~h}$. GCs treated with flutamide exhibited significantly increased FBP1 expression at 2, 24 and $48 \mathrm{~h}$, and GCs treated with flutamide + testosterone exhibited significantly decreased FBP1 expression at 12 and $24 \mathrm{~h}$, and increased expression at $48 \mathrm{~h}(\mathrm{P}<0.05)$, as presented in Fig. 4.

FBP1 total protein expression in GCs and TICs. As determined by western blot analysis, the protein expression levels of FBP1 were higher in the GCs of the T and F+T groups compared with the CTR group $(\mathrm{P}<0.05)$. There was no significant difference in FBP1 protein expression in the TICs of the $\mathrm{T}$ group compared with the CTR group; however, expression in the TICs of the F+T group was significantly lower than in the CTR group (Figs. 5 and 6).

Effects of testosterone on the FBPI signaling pathway in GCs and TICs. Using RT-qPCR, the mRNA expression levels of FBP1 and PCK1 were significantly increased in GCs treated with testosterone compared with in the CTR group, whereas testosterone significantly inhibited FOXO1 and peroxisome proliferator-activated receptor $\gamma$ coactivator $1 \alpha$ $(\mathrm{PGC}-1 \alpha)$ expression $(\mathrm{P}<0.05)$. Flutamide promoted the expression of FOXO1, and inhibited the mRNA expression of FBP1 and PGC-1 $\alpha$ in GCs $(\mathrm{P}<0.05)$. In TICs, testosterone and flutamide treatment inhibited the mRNA expression of FOXO1 and G6PC, and promoted the mRNA expression of PCK1 $(\mathrm{P}<0.05)$. There were no significant differences in FBP1 mRNA expression in TICs treated with testosterone or flutamide (Fig. 7).

\section{Discussion}

Gluconeogenesis mainly occursin the liver; hepatic gluconeogenesis and the insulin signaling pathway are dependent on several key enzymes, including G6 PC, PCK1, and upstream regulatory molecules FOXO1 and PGC- $1 \alpha$.

FBP can catalyze the hydrolysis of fructose-1,6-diphosphate to fructose-6-phosphate and inorganic phosphate. Mammals have two versionsof the FBP gene, the liver type (FBP1) that is found with in tissues associated with gluconeogenesis, such as the liver, kidney and digestive tract; andthe muscle type (FBP2), which only exists in skeletal muscle. Insulin inhibits FOXO1 through Akt-mediated phosphorylation and nuclear exclusion, and inhibits G6 PC and PCK1 gene expression (23). 
A

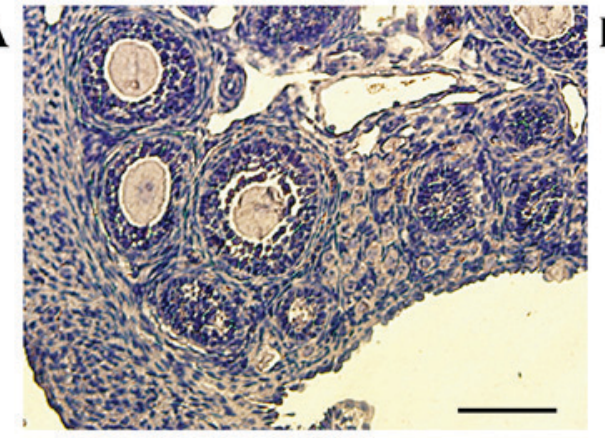

C

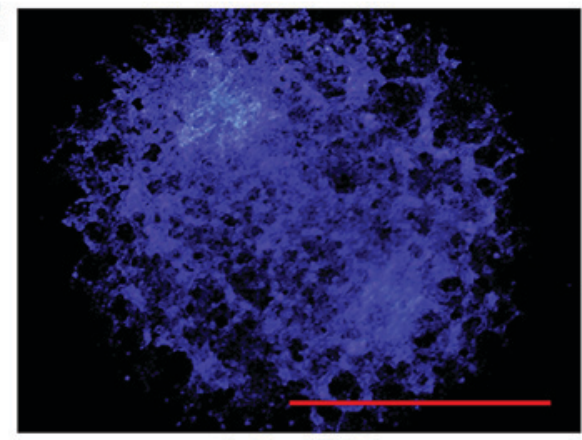

E

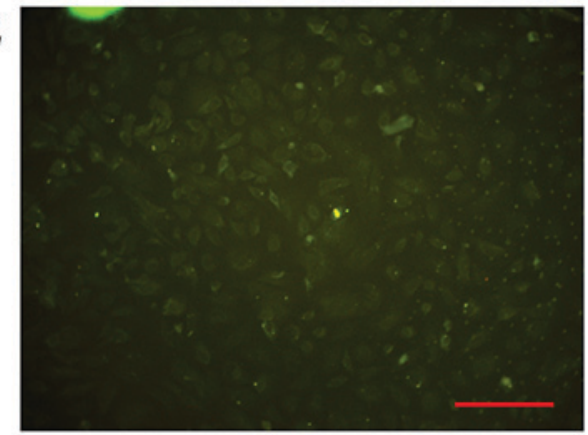

B

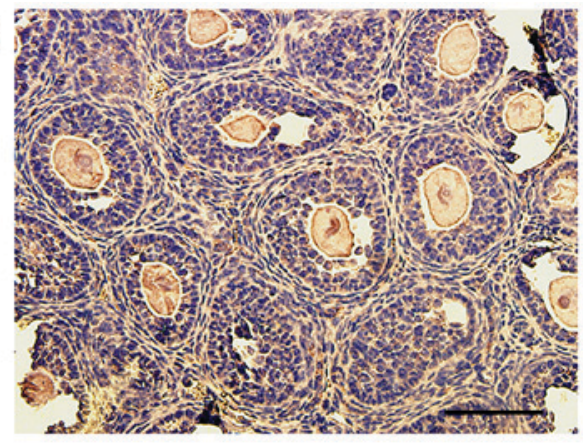

D

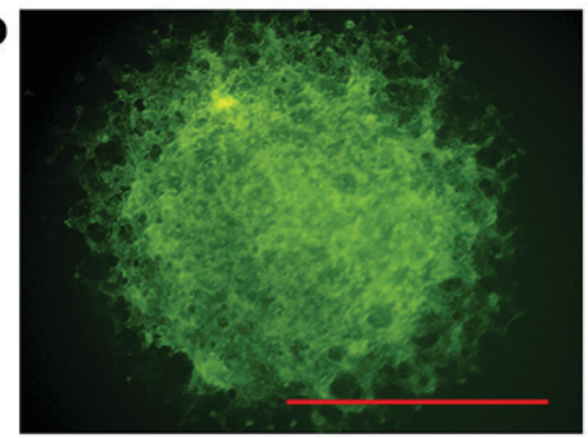

F

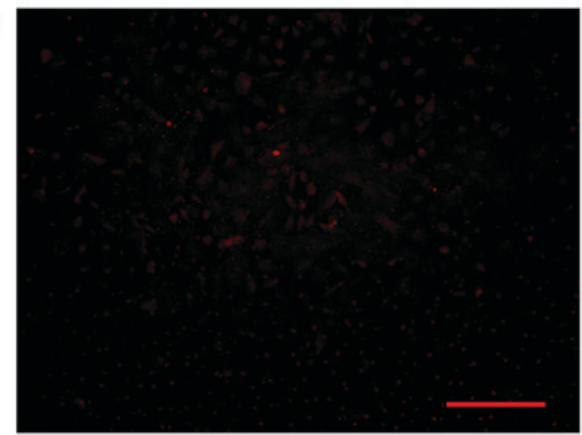

Figure 3. Detection of ovarian FBP1 expression using immunohistochemistry and immunofluorescence staining. (A) Mouse ovarian tissue sections of the control group were analyzed by immunohistochemical staining using the FBP1 antibody. (B) FBP1 protein was mainly expressed in the ovarian oocytes, granulosa cells and theca-interstitial cells of follicles cultured in vitro. (C and D) GCs expressed FBP1, follicles containing green fluorescent protein-positive GCs (green, anti-FBP1 antibody for immunofluorescence; blue, DAPI immunofluorescence). (E) Immunofluorescence analysis of FBP1 in mice GCs, FBP1 was mainly expressed in the cytoplasm and nucleus (green, anti-FBP1 antibody for immunofluorescence). (F) Immunofluorescence analysis of FBP1 in mice TICs, FBP1 was mainly expressed in the cytoplasm and nucleus (green, anti-FBP1 antibody for immunofluorescence). Scale bar, $100 \mu \mathrm{m}$.

PGC-1 is a key modulator of hepatic gluconeogenesis and a central target of the insulin-cAMP axis in the liver, which can induce FBP1, G6 PC and PCK1, resulting in an increased glucose output (24).

PCOS is the most common endocrinopathy among reproductive-aged women, and is a common cause of anovulatory infertility and menstrual cycle abnormalities associated with hypersecretion of $\mathrm{LH}$ and insulin. In addition, it is associated with hyperandrogenism in $5-10 \%$ of reproductive women worldwide, as well as an increased risk of type 2 diabetes and cardiovascular disease (25). Via a nationwide epidemiological survey, a previous study identified that PCOS had an incidence rate between 6 and $8 \%$ in Chinese women of reproductive age $(26,27)$. Furthermore, in our study population, the hyperandrogenism phenotype accounted for $20-60 \%$ of patientswith PCOS $(28,29)$. PCOS is associated with significant familial aggregation, and frequently occurs in first-degree relatives; the rates of PCOS in mothers and sisters of patients with PCOS are reported at 24 and $32 \%$, respectively. However, the risk was higher when considering untreated premenopausal women only (30). Although 17 genes have been identified in correlation with PCOS by GWAS, genes were detected mainly through a single GWAS; verification in a larger population has not been performed and studies of the underlying molecular cell biology have yet to be conducted; therefore, the candidate genes for the pathogenesis of PCOS have yet to be revealed (27). A range of animal models, including rodents, sheep and nonhuman primates, has been established in the study of PCOS. However, at present, an animal model that mimics all features associated with human PCOS has not been established. The present study used murine follicles, GCs and TICs as are search model to verify the alterations in FBP1 during abnormal development of ovarian follicles caused by high concentrations of testosterone.

It has previously been identified that androgens suppress female fetal renal gluconeogenesis in an ovine model of PCOS (31). At present, few studies have reported whether key enzymes of gluconeogenesis in mammalian ovarian tissues function optimally in PCOS, particularly FBP1 (32). The 


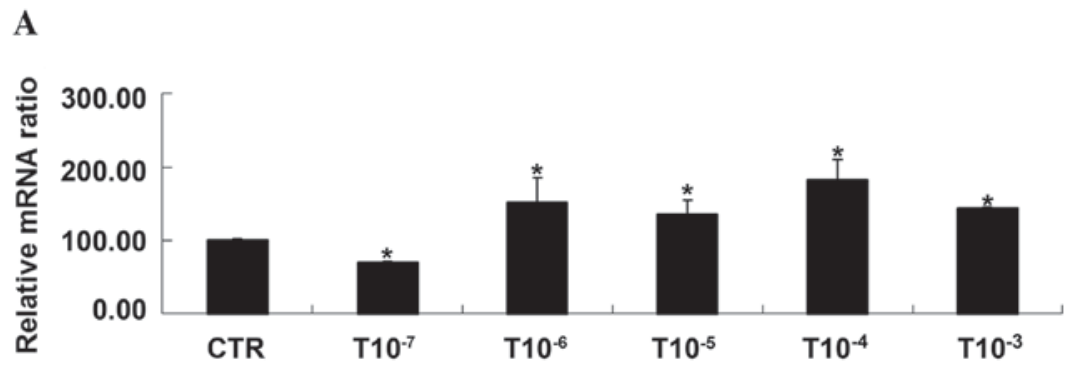

B

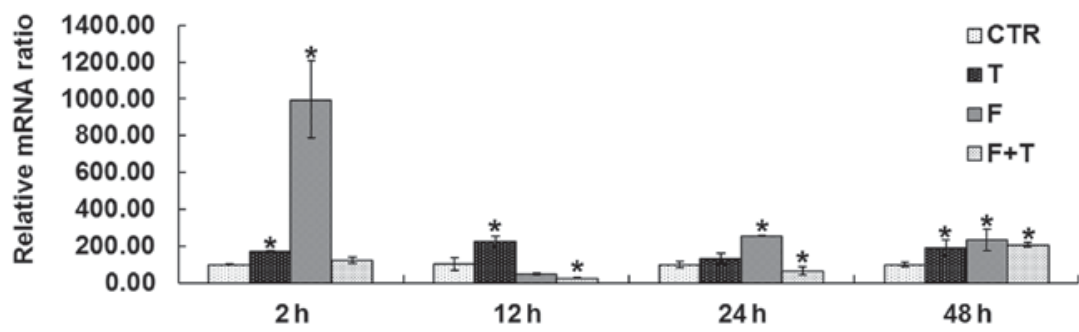

Figure 4. Effects of testosterone on FBP1 mRNA expression in GCs. (A) Expression of FBP1 was significantly increased in GC streated with $1 \times 10^{-6}$, $1 \times 10^{-5}$, $1 \times 10^{-4}$ and $1 \times 10^{-3} \mathrm{~mol} / 1$ testosterone compared with in the CTR group, ${ }^{*} \mathrm{P}<0.05$ vs. CTR group. (B) FBP1 mRNA expression was significantly increased in GCs treated with testosterone for 2,12 and $48 \mathrm{~h}$ compared with the CTR group at the same time. FBP1 mRNA expression was increased in GCs treated with flutamide + testosterone at $48 \mathrm{~h}$ compared with the CTR group. Treatment of GCs with flutamide led to a significant upregulation in FBP1 expression at 2 , 24 and $48 \mathrm{~h}$ compared with the CTR group. Conversely, when treated with flutamide + testosterone, mRNA expression in GCs was significantly decreased at 12 and $24 \mathrm{~h} .{ }^{~} \mathrm{P}<0.05$ vs. respective CTR group. CTR, control group (no testosterone treatment); T, testosteronetreatment group; F, flutamide treatment group; $\mathrm{F}+\mathrm{T}$, flutamide + testosterone group; FBP1, fructose-1,6-bisphosphatase 1; GC, granulosa cell.
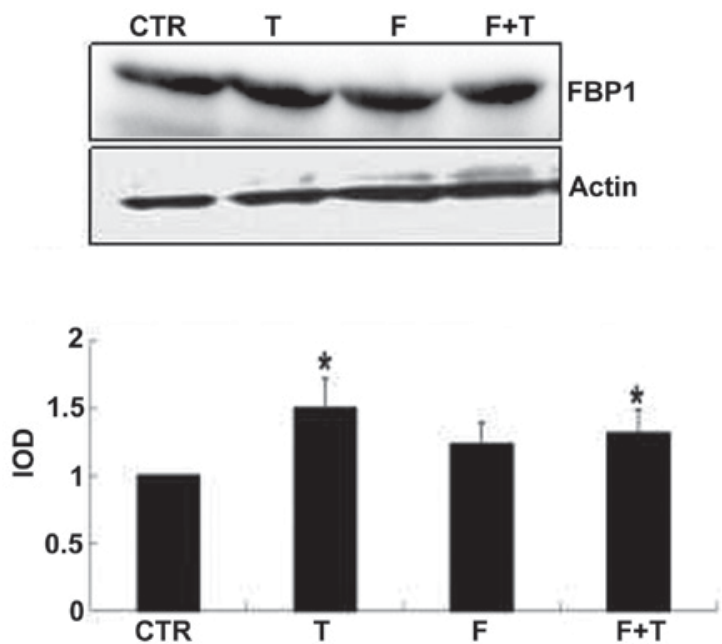

Figure 5. Western blot analysis of FBP1 protein expression in GCs. ${ }^{*} \mathrm{P}<0.05 \mathrm{vs}$ CTR group. CTR, control group (no testosterone treatment); T, testosteronetreatment group; F, flutamide treatment group; F+T, flutamide + testosterone group; FBP1, fructose-1,6-bisphosphatase 1; GC, granulosa cell; IOD, integrated optical density.

present study confirmed that androgens servea dual role in follicle development and affected follicular hormone secretion; $1 \times 10^{-5} \mathrm{~mol} / 1$ testosterone treatment stimulated GC and TIC development, whereas excessive testosterone inhibited their development. In addition, FBP1 was detected by immunofluorescence staining and it was identified that FBP1 was primarily expressed in ovarian oocytes, GCs and TICs. Furthemore, FBP1 protein was significantly expressed in GCs of the 14-day cultured follicle, and in the cytoplasm and
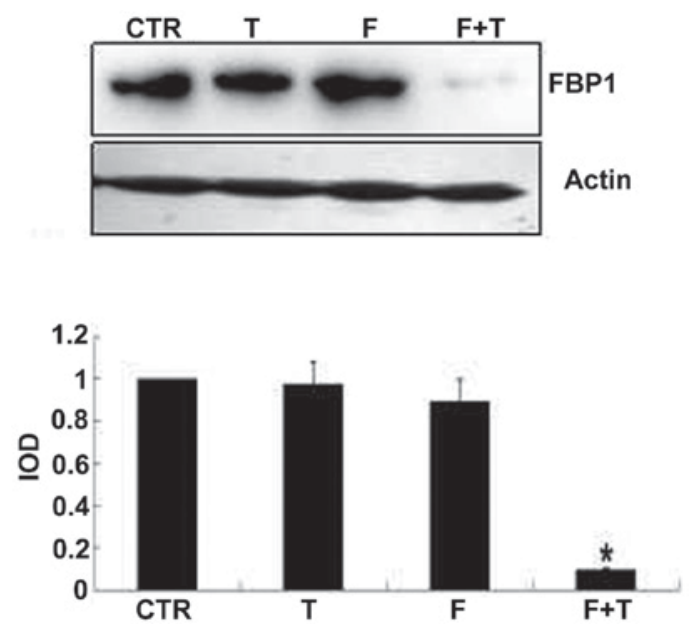

Figure 6. Western blot analysis of FBP1 protein expression in TICs. FBP1 expression was significantly reduced in the $\mathrm{F}+\mathrm{T}$ group. ${ }^{*} \mathrm{P}<0.05$ vs. CTR group. CTR, control group (no testosterone treatment); T, testosterone treatment group; F, flutamide treatment group; F+T, flutamide + testosterone group; FBP1, fructose-1,6-bisphosphatase 1; TIC, theca-interstitial cell; IOD, integrated optical density.

nucleiof GCs and TICs in vitro. Testosterone increased FBP1 expression of GCs at specific time intervals and testosterone concentrations. A high concentration of testosterone was able to increase the expression of FBP1 protein in GCs; however, it did not affect FBP1 expression in TICs. Conversely, treatment with flutamide and testosterone led to a decrease in FBP1 protein in GCs and TICs. Potentially, flutamide may competitively bind to androgen receptors. In addition, the main genes of the FBP1 signaling pathway were detected, and 


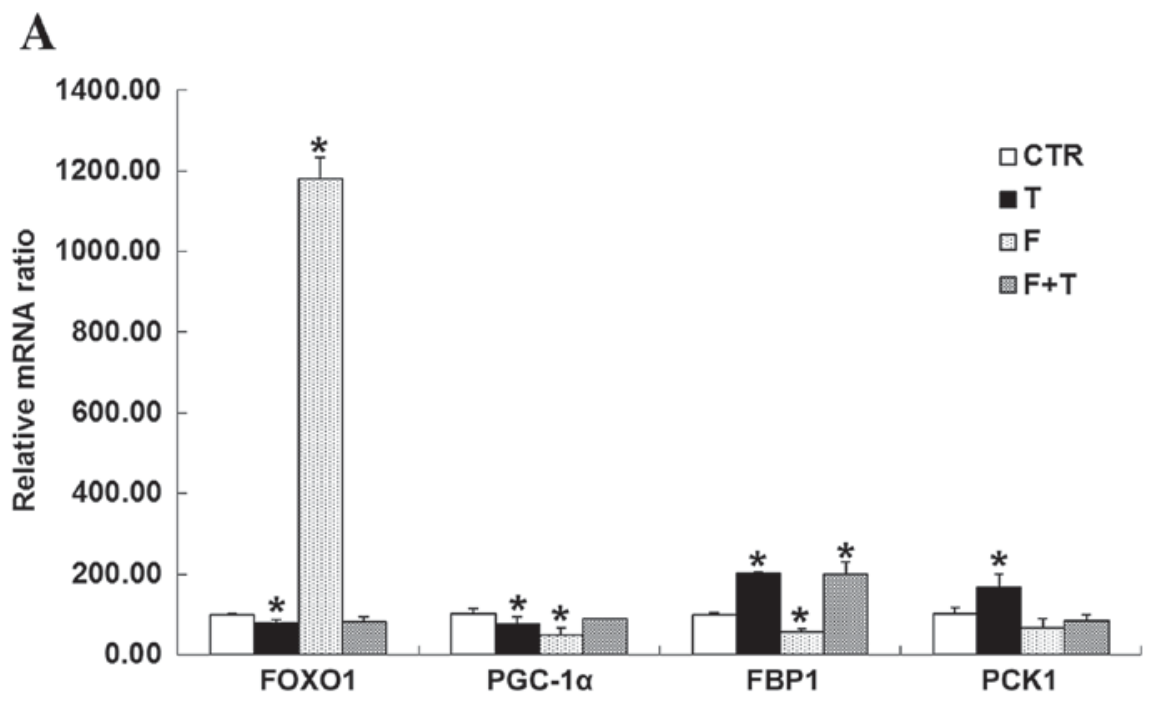

B

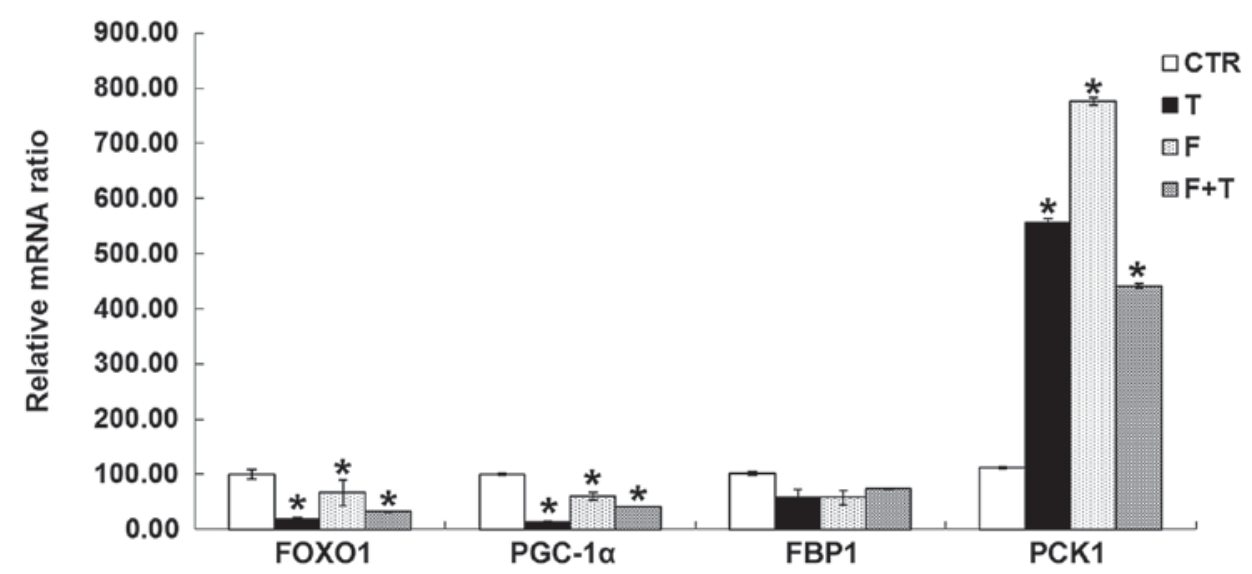

Figure 7. Effects of testosterone and/or flutamide on the expression of FBP1 signaling pathway genes in GCs and TICs. (A) Testosterone induced a significant increase in the mRNA expression levels of FBP1 and PCK1 in GCs compared with the CTR group, whereas testosterone significantly inhibited FOXO1 and PGC-1 $\alpha$ mRNA expression. "P $<0.05$ vs. respective CTR group. Flutamide promoted the expression of FOXO1, and inhibited the expression of FBP1 and PGC- $1 \alpha$ mRNA in GCs compared with the CTR group. " $\mathrm{P}<0.05$ vs. respective CTR group. (B) In TICs, testosterone or flutamide, or a combination of the two inhibited the mRNA expression of FOXO1 and G6PC compared with the CTR group, but promoted the mRNA expression of PCK1. "P<0.05 vs. respective CTR group. There was no significant effect on the expression of FBP1 mRNA in TIC by testosterone or fluoride, P $>0.05$. CTR, control group (no testosterone treatment); T, testosteronetreatment group; F, flutamide treatment group; F+T, flutamide + testosterone group; FOXO1, forkhead box protein O1; PGC-1 $\alpha$, peroxisome proliferator-activated receptor $\gamma$ coactivator $1 \alpha$; FBP1, fructose-1,6-bisphosphatase 1; PCK1, phosphoenolpyruvate carboxykinase 1; TIC, theca-interstitial cell; GC, granulosa cell; G6PC, glucose-6-phosphatase catalytic subunit.

the results demonstrated that the mRNA expression levels of FBP1 and PCK1 were significantly increased in GCs treated with testosterone, whereas a high concentration of testosterone significantly inhibited FOXO1 and PGC-1 expression. In addition, flutamide was able to promote the expression of FOXO1 and inhibit the mRNA expression of FBP1 and PGC-1 in GCs. In TICs, testosterone or flutamide was able to inhibit the mRNA expression of FOXO1 and G6 PC, and promote the mRNA expression of PCK1. These findings may be associated with the abnormal metabolism of insulin and abnormal glucose metabolism induced by high concentrations of testosterone. Furthermore, identification of the role and specific mechanisms of FBP1 in the development of PCOS is required in order to verify this theory infuture FBP1 gene knockout mice experiments.
In conclusion, the present study demonstrated that the FBP1 signaling pathway may be involved in normal follicle growth, as well as in hyperandrogenism-induced abnormal development of follicles; however, the specific mechanism requires further investigation.

\section{Acknowledgements}

The authors would like to thank the staff members of this trial, our colleagues and all the study staff for their efforts in collecting and ensuring the accuracy of the data. This project was supported by grants from the Natural Science Foundation of Shandong Province (grant no. ZR2012HL15) and the Postdoctoral Innovation Foundation of Shandong Province (grant no. 201203052). 


\section{References}

1. Chang C, Lee SO, Wang RS, Yeh S and Chang TM: Androgen receptor (AR) physiological roles in male and female reproductive systems: Lessons learned from AR-knockout mice lacking AR in selective cells. Biol Reprod 89: 21, 2013.

2. Shea LD, Woodruff TK and Shikanov A: Bioengineering the ovarian follicle microenvironment. Annu Rev Biomed Eng 16: 29-52, 2014.

3. Kim JY, Xue K, Cao M, Wang Q, Liu JY, Leader A, Han JY and Tsang BK: Chemerin suppresses ovarian follicular development and its potential involvement in follicular arrest in rats treated chronically with dihydrotestosterone. Endocrinology 154 2912-2923, 2013.

4. Dumesic DA, Oberfield SE, Stener-Victorin E, Marshall JC, Laven JS and Legro RS: Scientific statement on the diagnostic criteria, epidemiology, pathophysiology, and molecular genetics of polycystic ovary syndrome. Endocr Rev 36: 487-525, 2015

5. McGee WK, Bishop CV, Bahar A, Pohl CR, Chang RJ, Marshall JC, Pau FK, Stouffer RL and Cameron JL: Elevated androgens during puberty in female rhesus monkeys lead to increased neuronal drive to the reproductive axis: A possible component of polycystic ovary syndrome. Hum Reprod 27 531-540, 2012

6. Usadi RS and Legro RS: Reproductive impact of polycystic ovary syndrome. Curr Opin Endocrinol Diabetes Obes 19: 505-511, 2012.

7. Shi Y, Zhao H, Shi Y, Cao Y, Yang D, Li Z, Zhang B, Liang X, $\mathrm{Li} \mathrm{T}$, Chen J, et al: Genome-wide association study identifies eight new risk loci for polycystic ovary syndrome. Nat Genet 44 : 1020-1025, 2012.

8. Makieva S, Saunders PT and Norman JE: Androgens in pregnancy: Roles in parturition. Hum Reprod Update 20: 542-559, 2014.

9. Lebbe $\mathrm{M}$ and Woodruff TK: Involvement of androgens in ovarian health and disease. Mol Hum Reprod 19: 828-837, 2013.

10. Connolly F, Rae MT, Späth K, Boswell L, McNeilly AS and Duncan WC: In an ovine model of polycystic ovary syndrome (PCOS) prenatal androgens suppress female fetal renal gluconeogenesis. PLoS One 10: e0132113, 2015.

11. Nicol LE, O'Brien TD, Dumesic DA, Grogan T, Tarantal AF and Abbott DH: Abnormal infant islet morphology precedes insulin resistance in PCOS-like monkeys. PLoS One 9: e106527, 2014.

12. Takagi D, Ben-Ari J, Nemet D, Zeharia A and Eliakim A Recurrent infantile hypoglycemia due to combined fructose-1,6-diphosphatase deficiency and growth hormone deficiency. J Pediatr Endocrinol Metab 26: 761-763, 2013.

13. Drabovich AP, Pavlou MP, Dimitromanolakis A and Diamandis EP: Quantitative analysis of energy metabolic pathways in MCF-7 breast cancer cells by selected reaction monitoring assay. Mol Cell Proteomics 11: 422-434, 2012.

14. Thorn SR, Sekar SM, Lavezzi JR, O'Meara MC, Brown LD, Hay WW Jr and Rozance PJ: A physiological increase in insulin suppresses gluconeogenic gene activation in fetal sheep with sustained hypoglycemia. Am J Physiol Regul Integr Comp Physiol 303: R861-R869, 2012.

15. Romero S and Smitz J: Exposing cultured mouse ovarian follicles under increased gonadotropin tonus to aromatizable androgens influences the steroid balance and reduces oocyte meiotic capacity. Endocrine 38: 243-253, 2010.

16. Roland AV, Nunemaker CS, Keller SR and Moenter SM: Prenatal androgen exposure programs metabolic dysfunction in female mice. J Endocrinol 207: 213-223, 2010.
17. Zhang CP, Yang JL, Zhang J, Li L, Huang L, Ji SY, Hu ZY, Gao F and Liu YX: Notch signaling is involved in ovarian follicle development by regulating granulosa cell proliferation. Endocrinology 152: 2437-2447, 2011.

18. Itami S, Yasuda K, Yoshida Y, Matsui C, Hashiura S, Sakai A and Tamotsu S: Co-culturing of follicles with interstitial cells in collagen gel reproduce follicular development accompanied with theca cell layer formation. Reprod Biol Endocrinol 9: 159, 2011.

19. Yang JL, Zhang CP, Li L, Huang L, Ji SY, Lu CL, Fan CH, Cai H, Ren Y, Hu ZY, et al: Testosterone induces redistribution of forkhead box-3a and down-regulation of growth and differentiation factor 9 messenger ribonucleic acid expression at early stage of mouse folliculogenesis. Endocrinology 151: 774-782, 2010.

20. Forsgren KL and Young G: Stage-specific effects of androgens and estradiol-17beta on the development of late primary and early secondary ovarian follicles of coho salmon (Oncorhynchus kisutch) in vitro. Biol Reprod 87: 64, 2012.

21. Lenie $S$ and Smitz J: Functional AR signaling is evident in an in vitro mouse follicle culture bioassay that encompasses most stages of folliculogenesis. Biol Reprod 80: 685-695, 2009.

22. Livak KJ and Schmittgen TD: Analysis of relative gene expresison data using real-time quantitiative PCR and the 2(-Delta Delta C(T)) method. Methods 25: 402-408, 2001

23. Zhang P, Tu B, Wang H, Cao Z, Tang M, Zhang C, Gu B, Li Z, Wang L, Yang Y, et al: Tumor suppressor p53 cooperates with SIRT6 to regulate gluconeogenesis by promoting FoxO1 nuclear exclusion. Proc Natl Acad Sci USA 111: 10684-10689, 2014.

24. Puigserver P, Rhee J, Donovan J, Walkey CJ, Yoon JC, Oriente F, Kitamura Y, Altomonte J, Dong H, Accili D and Spiegelman BM: Insulin-regulated hepatic gluconeogenesis through FOXO1-PGC-1alpha interaction. Nature 423: 550-555, 2003.

25. Walters KA, Allan CM and Handelsman DJ: Rodent models for human polycystic ovary syndrome. Biol Reprod 86: 149, 2012.

26. Li T, Wu K, You L, Xing X, Wang P, Cui L, Liu H, Cui Y, Bian Y, Ning Y, et al: Common variant rs9939609 in gene FTO confers risk to polycystic ovary syndrome. PLoS One 8: e66250, 2013.

27. Chen ZJ, Zhao H, He L, Shi Y, Qin Y, Shi Y, Li Z, You L, Zhao J, Liu J, et al: Genome-wide association study identifies susceptibility loci for polycystic ovary syndrome on chromosome $2 \mathrm{p} 16.3$ 2p21 and 9q33.3. Nat Genet 43: 55-59, 2011.

28. Zhang HY, Guo CX, Zhu FF, Qu PP, Lin WJ and Xiong J: Clinical characteristics, metabolic features, and phenotype of Chinese women with polycystic ovary syndrome: A large-scale case-control study. Arch Gynecol Obstet 287: 525-531, 2013.

29. Chen Z: Polycystic ovary syndrome etiology and clinical research. J Reprod Med 16: 232, 2007.

30. Kahsar-Miller MD, Nixon C, Boots LR, Go RC and Azziz R: Prevalence of polycystic ovary syndrome (PCOS) in first-degree relatives of patients with PCOS. Fertil Steril 75: 53-58, 2001.

31. Connolly F, Rae MT, Späth K, Boswell L, McNeilly AS and Duncan WC: In an ovine model of polycystic ovary syndrome (PCOS) prenatal androgens suppress female fetal renal gluconeogenesis. PLoS One 10: e0132113, 2015.

32. Dupont $\mathbf{J}$ and Scaramuzzi RJ: Insulin signalling and glucose transport in the ovary and ovarian function during theovarian cycle. Biochem J 473: 1483-1501, 2016. 